\title{
Assessment of Quality of Life from HIV Counselling and Social Support among PLWHA Clinic Attendees in Specialist Hospital Yola, Adamawa State, Nigeria
}

\author{
Article by J E Chiegil ${ }^{1}$, K U Suru ${ }^{2}$, S O Adeyemi ${ }^{3}$, O F Martins ${ }^{4}$ \\ 1, 2, ${ }^{3}$ Texila American University Guyana \\ ${ }^{4}$ Department of Public Health, Federal Medical Centre Yola, Adamawa State, Nigeria \\ E-mail: ima.josef123@gmail.com ${ }^{1}$
}

\begin{abstract}
The purpose of the study was to assess the quality of life from HIV counselling and social support among PLWHIV clinic attendees in specialist hospital Yola. A descriptive research was conducted. Data was collected using a structured questionnaire, where a total of 370 randomly selected PLWHA adult from the age of 18 years and above attending clinic at Specialist Hospital Yola participated in this study. Data was analysed using SPSS version 21.0. Descriptive statistics was used to analyse the demographic variables while tables and charts were used for the presentation of results. Pearson's correlation was used between relevant variables while linear regression was used to predict outcomes. Statistical significance of this study was set at $P \leq 0.05$. The results indicate that most of the respondents were well informed (78.2\%) about basic issues in HIV. This was like their levels of counselling and social support received (71.7\%), perceived self-efficacy (63.8\%), self-reported treatment adherence (80\%) and self-reported quality of life (64.3\%). This revealed that correct information, knowledge and awareness about basic issues in HIV and social support are very crucial to improving the behavioural skills and increase the level of confidence among PLWHA to perform adherent behaviours thereby significantly improve the quality of life of PLWHA clinic attendees.
\end{abstract}

Keywords: People living with HIV/AIDs, Quality of life, treatment adherence, information and social support.

\section{Introduction}

The menace of HIV/AIDS has become a global threat to human existence owing to its rapid spread and absence of any known cure after several decades of its existence. Over 34million people across the world are living with HIV/AIDS and Nigeria has the second highest number in the world after South Africa (USAID, 2010). With approximately 3million people living with HIV/AJDS (PLWHA), Nigeria makes about $9 \%$ of the global HIV burden (USAID, 2010). To reduce the effect of this threat to a bearable minimum, scholars agree that treatment adherence is indispensable (Mannheimer et al., 2005). This is an obvious fact, notwithstanding, many PLWHA in developing countries still find it tasking to develop a positive adherent behaviour and thus, manifest very poor health outcomes. It has been suggested that lack of information, knowledge and awareness about basic issues concerning the infection and poor social support could be responsible for this gap. Studies indicate that PLWHA who enjoy better quality of life are those who are well informed and as such, combined strict adherence to anti-retroviral therapy (ART) with other forms of social support services (Heyer et al, 2010). There are strong evidences that psychosocial support affects the functioning of the immune system, self-care activities and other illness behaviours and can considerably contribute to improving the health outcomes of PLWHA besides adherence to ART (Adedimeji et al, 2010). It is also documented that correct information and social support will enhance the self-efficacy of PLWHA to perform adherent behaviours (Scott et al, 2003). In a study carried out in Italy on adherence to ART, findings reveal that several-related information and motivation have a significant relationship to adherence related behavioural skills, while behavioural skills were also significantly associated to self- reported optimal adherence (Starace et al, 2006). Again, social support has been identified by health planners as complementary health care which can contribute to positive health behaviours and improve the quality of life of PLWHA (Lyttleton 2004). Quality of life must do with the ability of individuals to effectively carryout their daily routines. Studies show that many PLWHA find it quite tasking attending to their daily routine activities, 
participate in moderately vigorous physical activities or have enough vitality to engage in active social life while managing HIV/AIDS (Basavaraj et al, 2010). Effective social support and correct information have proven to be very useful for PLWHA globally (De Barros et al. 2004). Beyond participation in social support groups, research has also identified other forms of support such as companionship, affection, nutritional support, financial support where they get access to drugs and basic information, palliative care, psychosocial support, end-of-life care, caring for care-givers, community based support, governmental and non-governmental organizational support and some care supports that are also very useful to PLWHA (Christopher J.E 2001). The above can broadly be fitted into institution-based and home-based support with each of them having the potentials to improve quality of life effectively implemented. Evolving suggestions show that home-based support is much more perceived by PLWHA as improving their wellbeing than institution-based support which seems the highly promoted by health planners. In a study carried out in Iran, relative members were the most important people in the life of PLWHA. The study concludes that it is unlikely that available support and the place of relatives can be replaced by other network members because of the strong and stable nature of ties between family members (Forouzan, et al, 2012). Therefore, relative members must understand the needs of HIV/AIDS patients and help them to manage the new conditions of life with HIV/AIDS to improve their psychological and social conditions. Another striking aspect of HIV/AIDS is the gender perspective to depression among PLWHA which seem to greatly affect their general health outcomes. Studies reveal that women present more severe symptoms of intensity of depression than men and those individuals with depressive symptoms had lower scores of qualities of life than individuals without these symptoms (Reis et al, 2011). Regrettably, many PLWHA within this study area do not still embrace social support either at home or institutions after confirming their HIV positive status due to shame, fear of stigma and discrimination or other factors and as such, routinely breakdown in health at the expense of their expected social and civic responsibilities. Although social support activities generally tend to undermine the individual's full confidentiality, acceptance of the reality of this new status and constant interactions with others in the same condition is more likely to provide the needed social therapy of coping with such discriminations and leading a positively healthy live.

Every day, many more persons are being infected with HIV and AIDS, the world over with Nigeria so far ranking second. Latest report on HIV/AIDS in Nigeria ranks Adamawa State e as topmost with a prevalence of $1.9 \%(\mathrm{FMOH}, 2012)$ while Yola North is also one of the leading LGAs with the disease burden in Adamawa State (SACA, 2013). Records show that optimal treatment adherence among the greater proportion of PLWHA is still a mirage in Nigeria and the resultant effect is quite 'devastating. There are indications that most of those with suboptimal adherence behaviours lack social support and basic information concerning their illness.

It is therefore beneficial, to embark on this research to assess the quality of life from HIV counselling and social support among PLWHA clinic attendees in Specialist Hospital Yola, Adamawa State, Nigeria.

Limitations of this study include an absence of pill count to ensure accuracy and reduce the subjectivity of self-reported treatment adherence and the reliance of self- reports that could either over or underestimate adherence.

Results from this study will guide health planners to be more intentional in designing and implementing programs to improve the level of counselling and social support PLWHA receive and their understanding of basic issues pertaining to their illness.

The objective of this research was to assess the quality of life from HIV counselling and social support among PLWHA and determine whether information, knowledge and awareness about basic issues in HIV will have any significant relationship with social support among PLWHA clinic attendees in Specialist Hospital Yola.

\section{Methodology}

This is a descriptive research with two sources of information; primary and secondary.

The primary source included information sourced from questionnaire, face to face interview and observation.

The secondary source included information sourced from text books, journals, conference notes, seminar papers, workshop presentations, magazines, newspapers, periodicals, internet etc., 
Specialist Hospital Yola, located in the heart of Jimeta town, Yola North LGA of Adamawa State is one of the HIV comprehensive sites in in the state

At least, 13, 446 PLWHA from within and outside Adamawa State have cumulatively utilized Specialist Hospital Yola from 2007 when HIV/AIDS services formally began in the area, till date (SACA, 2013).

A total of 370 PLWHA adult from the age of 18 years and above attending clinic at Specialist Hospital Yola consented and participated in this study.

Children and adolescents below 18 years were excluded from this study due to how cumbersome it was to obtain their consent through their respective parents.

Data was collected using well-structured questionnaires from PLWHA clinic attendees in Specialist Hospital Yola, on clinic days, during clinical periods. The questionnaires were intervieweradministered, through trained counsellors.

This questionnaire was divided into five sections covering socio-demographic characteristics, HIV-Information, HIV-Information Comprehension, Readiness and social support to adhere to treatment instructions, as well as self-Reported adherence to the counseling information received.

Section B comprised of 14 questions with "Yes" or "No" responses enquiring whether messages related to the statements were delivered to the respondents during the counseling or information session(s), measured on a 14 point scale.

The next section measuring motivation had 3 parts: Section C, part one consisted of self-reported level of comprehension of HIV related information (whether counseling information were received and understood) with ordinal response pattern ranging from well "understood" to "not understood", and whether such information was not given. This was measured on a 28 point scale. Section C, part 2 contains some application questions that verified or confirmed respondents' level of comprehension of the HIV related information as reported in section C Part 1 above (measured on a 6 points scale). In this section, three alternative choices (answers) were provided to choose as many answers as they wanted: Correct answers, were accorded 1 point, and all incorrect answers, 0 point. Section C, part 3 enquired whether clients were motivated with incentives and reinforcements. It was measured on 18 point scale with response pattern, "strongly agree" to "strongly disagree."

Section D measured respondents" social support to adhere received using ordinal (likert) scale response pattern ranging from "strongly agree" to "strongly disagree", on a 27 point scale.

Section D measured respondents' Readiness to adhere to the instructions received using ordinal (likert) scale response pattern ranging from "strongly agree" to "strongly disagree", on a 27 point scale.

Finally, Section F measured the self-reported level of Adherence to HIV Counseling Information with response range of "always" to "never", measured on 32 points scale (adopted from Morisky's self-reported medication adherence tool).

Data was analysed using SPSS version 21.0. Descriptive statistics was also used to analyse the demographic variables while tables and charts were used for the presentation of results. Pearson's correlation was used between relevant variables while linear regression was used to predict outcomes. Statistical significance of this study was set at $\mathrm{P} \leq 0.05$.

This study was conducted in accordance with ethical research guidelines and in compliance with the legal requirements for the study. Ethical clearance/written informed consent/ permission was obtained from the Adamawa State Ministry of Health (MOH).

\section{Results and discussions}

The mean age of respondents was 39.26 with a range of 46 . Young adults represented $29.7 \%$, mature adults; $49.7 \%$ and older adults; $20.5 \%$. Distribution of the respondents by sex showed that males represented $(32.2 \%)$ of the study population while the females; $67.8 \%$.

Most (32\%) respondents were married, 29.5\% single, $12.7 \%$ divorced, 5.7\% separated and $19.5 \%$ widowed. Majority (82.7\%) of respondents were Christians. Majority (62.7\%) had completed their secondary education with minority $(5.4 \%)$ had no form of formal education. The major tribe represented among respondents was Laka; $44.9 \%$, and most (39.2\%) respondents were unemployed (Table 1).

The mean score analysis of the variable in table 3 shows the mean score of variables for determination in this study. Information, knowledge and awareness of respondents about basic issues 
DOI: $10.21522 /$ TIJPH.2013.05.04.Art001

ISSN: $2520-3134$

in HIV was (7.04 \pm 2.373$)$ on a 9-point scale, representing (78.2\%) level of awareness. Social support was (32.30 \pm 8.020$)$ on a 45-point scale which represents $(71.7 \%)$ while the mean score for selfefficacy was $(13.40 \pm 5.437)$ on a 21-point scale. This figure represents $(63.8 \%)$ level of self-efficacy of the study population. The average for treatment adherence among respondents was (14.38 \pm 4.091$)$ on an 18-point scale, representing approximately $80 \%$ level of treatment adherence of the respondents and lastly, the average for self-reported quality of life from analysis was (15.44 \pm 6.359$)$ on a 24-point scale. This figure represents $(64.3 \%)$ level of quality of life.

Result from this study in table 4 shows that the correlation coefficient of analysis between information and social support $(\mathrm{r}=0.8)$ and $\mathrm{P}<0.0001$ while $(\mathrm{R} 2=81.9 \%)$ and $\mathrm{P}<0.0001$ in table 5 .

Findings from this study in table 4 reveal that there was a positive correlation between information and self-efficacy $(r=0.8)$ and $\mathrm{P}<0.0001$. Linear regression analysis in table 5 shows the square of the coefficient of determination $(\mathrm{R} 2=67.4 \%)$ and $\mathrm{P}<0.0001$.

Result of the correlation analysis between information and adherence in table 4 reveals that $=0.9$ ) and $\mathrm{P}<0.0001$ while regression analysis in table 5 shows ( $\mathrm{R} 282.5 \%)$ and $\mathrm{P}<0.0001$.

Correlation analysis in table 4 reveals that social support was positively correlated with selfefficacy $(\mathrm{r}=0.8)$ and $\mathrm{P}$-value was significant at $\mathrm{P}<0.0001$. Result of the regression analysis in table 5 shows that $(\mathrm{R} 280.1 \%)$ and $\mathrm{P}<0.0001$.

The correlation coefficient of analysis between social support and treatment adherence in table 4 reveals that $(\mathrm{r}=0.8)$ and $\mathrm{P}$-value was significant at $\mathrm{P}<0.000$ lwhile table 5 shows the coefficient of determination (R2 66.6\%) and $\mathrm{P}<0.0001$.

Result of the correlation analysis between self-efficacy and treatment adherence in table 4 reveals that $(\mathrm{r}=0.9)$ and $\mathrm{P}<0.0001$ while regression analysis in table 5 shows $(\mathrm{R} 257.5 \%)$ and $\mathrm{P}<0.0001$.

There was a positive correlation between treatment adherence and QOL among respondents in Table 4. The correlation coefficient ( $\mathrm{r} 0.8)$ with $\mathrm{P}<0.0001$ while result of regression analysis in le 5 shows that $(\mathrm{R} 268.2 \%)$ and $\mathrm{P}<0.0001$.

Table 1. Demographic characteristics of respondent

\begin{tabular}{llll}
\hline & & Frequency & $\begin{array}{l}\text { Percent } \\
(\%)\end{array}$ \\
\hline Age & Young Adults $(18-35)$ & 110 & 29.7 \\
& Mature Adults $(36-50)$ & 184 & 49.7 \\
& Older Adults (>50) & 76 & 20.5 \\
\hline Sex & Male & 119 & 32.2 \\
& Female & 251 & 67.8 \\
\hline Marital & & & \\
Status & Married & 121 & 32.7 \\
& Single & 109 & 29.5 \\
& Divorced & 47 & 12.7 \\
& Separated & 21 & 5.7 \\
& Widowed & 72 & 19.5 \\
\hline Religion & & & \\
& Islam & 30 & 8.1 \\
& Christianity & 306 & 82.7 \\
& Traditional & 34 & 9.2 \\
\hline Educational & & & \\
Status & & & \\
& No formal education & 20 & 5.4 \\
& Primary & 48 & 13.0 \\
& Secondary & 232 & 62.7 \\
& Tertiary & 70 & 18.9 \\
\hline Tribe & & & \\
& Laka & 97 & 26.2 \\
& & &
\end{tabular}


Texila International Journal of Public Health

Volume 5, Issue 4, Dec 2017

\begin{tabular}{llll} 
& Bachama & 37 & 10.0 \\
& Hausa & 31 & 8.4 \\
\hline Occupation & & & \\
& Civil servant & 81 & 21.9 \\
& Self - employed & 144 & 33.9 \\
& Umemployed & 145 & 39.2 \\
\hline
\end{tabular}

Table 2. Descriptive statistics showing mean scores on variables in research Questions

\begin{tabular}{|l|l|l|l|}
\hline Variables & N & Mean \\
\cline { 2 - 4 } & Statistic & Statistic & Percent (\%) \\
\hline $\begin{array}{l}\text { Level of Information, Knowledge \& } \\
\text { Awareness measure on a 9-Point } \\
\text { Scale. }\end{array}$ & 370 & 7.04 & 78.2 \\
\hline $\begin{array}{l}\text { Social support 1: Reinforcing support } \\
\text { sub-variable measure on an 18- point } \\
\text { scale. }\end{array}$ & 370 & 11.28 & 62.6 \\
\hline $\begin{array}{l}\text { Social support 2: Enabling support } \\
\text { sub-variable measure on a 15- point } \\
\text { scale. }\end{array}$ & 370 & 12.05 & 80.3 \\
\hline $\begin{array}{l}\text { Social support 3: Informational } \\
\text { support sub-variable measure on a 12- } \\
\text { point scale. }\end{array}$ & 370 & 8.98 & 74.8 \\
\hline $\begin{array}{l}\text { Social support sub-variables 1, 2 \& 3 } \\
\text { measure on a 45-point scale }\end{array}$ & 370 & 32.30 & 71.7 \\
\hline $\begin{array}{l}\text { Self- Efficacy and Behavioural Skills } \\
\text { measure on a 21-point scale }\end{array}$ & 370 & 13.40 & 63.8 \\
\hline $\begin{array}{l}\text { Self-Reported Adherence to } \\
\text { Medication and Clinical Appointments } \\
\text { measure on an 18-point scale }\end{array}$ & 370 & 14.38 & 80 \\
\hline $\begin{array}{l}\text { Quality of Life Measures on a 24-point } \\
\text { scale }\end{array}$ & 370 & 15.44 & 64 \\
\hline
\end{tabular}

Table 3. Showing pearson's correlation analysis between variables

\begin{tabular}{|l|l|l|l|l|}
\hline S/N & \multicolumn{2}{|l|}{ Correlation Variables } & R & P-value \\
\hline 1 & Information & Social support & .818 & .0000 \\
\hline 2 & Information & Self-efficacy & .800 & .0000 \\
\hline 3 & Information & $\begin{array}{l}\text { Treatment } \\
\text { Adherence }\end{array}$ & .905 & .0000 \\
\hline 4 & Social support & Self-efficacy & .850 & .0000 \\
\hline 5 & Social support & $\begin{array}{l}\text { Treatment } \\
\text { Adherence }\end{array}$ & .826 & .0000 \\
\hline 6 & Self-efficacy & $\begin{array}{l}\text { Treatment } \\
\text { Adherence }\end{array}$ & .759 & .0000 \\
\hline 7 & $\begin{array}{l}\text { Treatment } \\
\text { Adherence }\end{array}$ & Quality of Life & .816 & .0000 \\
\hline
\end{tabular}


DOI: $10.21522 /$ TIJPH.2013.05.04.Art001

ISSN: $2520-3134$

Table 4. Showing linear regression analysis of variables

\begin{tabular}{|l|l|l|l|l|}
\hline S/N & $\begin{array}{l}\text { Independent Variable } \\
\text { (Predictor- Constant) }\end{array}$ & Dependent Variable & R2 & P-Value \\
\hline 1. & Information & Social Support & 819 & 0000 \\
\hline 2. & Social support & Information & 819 & 0000 \\
\hline 3. & Information & Self-Efficacy & 74 & 0000 \\
\hline 4. & Information & $\begin{array}{l}\text { Treatment } \\
\text { Adherence }\end{array}$ & 825 & 0000 \\
\hline 5. & Social Support & Self-Efficacy & 801 & 0000 \\
\hline 6. & Social Support & $\begin{array}{l}\text { Treatment } \\
\text { Adherence }\end{array}$ & 666 & 0000 \\
\hline 7. & Self-Efficacy & $\begin{array}{l}\text { Treatment } \\
\text { Adherence }\end{array}$ & 575 & 0000 \\
\hline 8. & $\begin{array}{l}\text { Information, social support } \\
\text { \& Self- efficacy }\end{array}$ & $\begin{array}{l}\text { Treatment } \\
\text { Adherence }\end{array}$ & 841 & 0000 \\
\hline 9. & Treatment Adherence & Quality of Life & 682 & 0000 \\
\hline
\end{tabular}

The age of respondents from this study ranged from 18-64 years with an average of 39.26. This is similar with previous studies in which mean age was 38.9 (Folasire et al, 2012). The implication of this to practice is that this is the most affected age group. Majority of the respondents were females $(63.8 \%)$. Although, this is in line with previous studies which noted that females more vulnerable to the infection and that they utilize medical services much more than their male counterparts (Whetten, 2004), the high representation of females in this study could be attributed to the fact that the health facility utilized for this study also provides prevention of mother-to-child transmission (PMTCT) of HIV services which is exclusive to women on antenatal care who are usually in large numbers. Most of the respondents from this study were married (32.2\%), but followed very closely by the singles (29.5\%) that are all within acceptable age-brackets for marriage. This foretells a great danger for oncoming suitors who may not have a foreknowledge of the HIV statuses of these singles who may over time, become more desperate to get married and as such, may not be always willing to disclose their statuses in order not to deter their suitors. Previous studies suggest that effective social support and reinforced counselling will improve self-disclosure abilities of PLWHA (Van Tam et al, 2012).

More than two-third of the respondents $(82.7 \%)$ were Christians and this is because Christianity is the dominant religion in the area. At least, $62 \%$ of the respondents have attained secondary education and Laka (Godogodo) which is the indigenous tribe recorded the highest number of respondents with about $(45 \%)$ of the total population. One striking aspect of the findings of this study is the fact that most of the respondents (39.2\%) were unemployed. Job abandonment due to depression and stigmatization has been identified in previous studies as one of the factors increasing the rate of unemployment among PLWHA (Liu, et al, 2013).

Most of the respondents were well informed (78.2\%) about basic issues in HIV. This was like their levels of counselling and social support received (71.7\%), perceived self-efficacy (63.8\%), selfreported treatment adherence (80\%) and self-reported quality of life (64.3\%). It is important to state here that though the level of treatment adherence of this study population was quite high, the standard for optimal adherence for PLWHA is $\leq 95 \%$ (Low-Beer et al, 2000).

The gap here could be attributed to the fact that the level of perceived self-efficacy of respondents which is an important predictor of adherence was relatively lower than all other variables. Findings from similar studies in the past reveal that an improvement in self-efficacy and behavioural skills will enhance the level of treatment adherence vis-à-vis quality of life (Amico et. al, 2005). IResults from relationships examined in this study were quite unique. Information, self-efficacy, social support and treatment adherence were significantly correlated with one another. There was also a significant relationship between treatment adherence and quality of life. However, while information and social support were mutual predictors of themselves, self-efficacy was predicted by both information and social support. Treatment adherence on the other hand was significantly dependent on the trio of information, social support and self-efficacy. Lastly, the quality of life of PLWHA was significantly dependent on treatment adherence. 
This result is consistent with the suggestions of the IMB that health-related information, motivation, and self-efficacy are important determinants of an individual's health behaviour (Fisher et al, 2003). It implies that if a person is well-informed, effectively motivated to act by the social support he receives, he is more likely to develop the enabling skills and confidence required to initiate and maintain health-enhancing behaviours that produce will improve his quality of life (Fisher et al, 2003). Previous studies which subjected the IMB model to an empirical test also identified significant relationships between variables under consideration in this study and observed that PLWHA need both accurate information as well as social support to enhance their adherent-behavioural skills which will culminate into optimal adherent behaviours (Amico et al, 2005). This implies that the more informed PLWHA are about their ailment, the more social services they are likely to be aware of and vice versa. To improve the level of adherence of PLWHA, there must be an uninterrupted channel through which they can access latest information on new trends and changes in their illness (Starace F et al, 2006).

Thus, poor access to information and motivation will reduce the behavioural skills of PLWHA (Population Council and Health Systems Trust, 2006). One striking aspect of this study is the fact that the QOL of PLWHA was significantly dependent on correct and consistent adherence to treatment. This position agrees with several conducted in the past. Adherence to ART significantly improved the quality of life of PLWHA in Zambia (Mweemba et al, 2010). In the same vein, participants who reported $100 \%$ adherence to treatment were observed to achieve significantly higher quality of life scores compared to those with poorer adherence in another study (Mannheimer et al, 2005). Interestingly, non-adherence to treatment has been observed to rapidly increase the viral load of PLWHA and as such, reduce their quality of life (Adedimeji et al, 2010). Per the National Collaborating Centre for Infectious Diseases, (2010), to improve adherence behaviours include diagnosing and treating depression, treating drug and alcohol dependence, strengthening the provider-client relationship, and fostering social support through the incorporation of partners and family members into the care plan. Every activity by health planners such as provision of correct information and other social support services must therefore be tailored towards increasing the abilities of PLWHA to optimally adhere to treatment since very little or nothing can be achieved about their quality of life without adherence.

\section{Conclusion}

Correct information, knowledge and awareness about basic issues in HIV and social support are very crucial to improving the behavioural skills and increase the level of confidence PLWHA to perform adherent behaviours. Treatment adherence is significantly dependent on the level of information, social support and self-efficacy among PLWHA as observed from this study.

The quality of life of PLWHA on the other hand is significantly dependent on positive treatment adherence behaviour. This includes adherence to medication, proper dozing; keeping to clinical appointment and coping with stigma among others. Finally, information, social support and adherence will significantly improve the quality of life of PLWHA clinic attendees in Specialist Hospital Yola.

Quality of life is a multidimensional concept whose definition and assessment remains controversial. HIV/AIDS represents a high economic impact from society point of view.

Overall self-perception of QOL has been shown to be a useful screening item for assessing QOL. QOL relates both to adequacy of the material circumstances and to personal feelings about these circumstances. As health is generally cited as one of the most important determinants of overall QOL, it has been suggested that QOL may be uniquely affected by specific disease process such as AIDS. There is lack of clarity in defining QOL and concomitant operational difficulties in it but still there is urgency in evaluating the QOL in HIV-infected individuals. Future studies should encompass the evaluation of more determinants of QOL among PLHA. The constellations of HIV-related symptoms negatively affect the QOL for people living with HIV infection. Effective management of symptoms is important for improving QOL and potentially for maintaining a complicated daily regimen of ART. As HIV disease is among the most devastating of illnesses, having multiple and profound effects upon all aspects of life, hence the evaluation of QOL is very important. Although research has suggested relationships among various psychosocial and spiritual factors, symptomatology, and physical health, much more research is still needed to document their potential influences on immune 
function, as well as health status, disease progression, and QOL among persons with HIV disease. It is also important to underline the role of consultation-liaison psychiatry in the diagnosis and treatment of HIV and AIDS. Stress management interventions for HIV-infected persons are a promising approach to facilitate positive adjustment.

It is therefore the recommendation of this study that health planners, support groups and caregivers should be more intentional in designing and implementing programs that will improve the level of social support PLWHA receive and their understanding of basic issues pertaining to their illness which will in turn; improve their treatment adherent behaviours and ultimately, their quality of life.

Since PLWHA are likely to spend more of their times with relatives at home, it is recommended that trainings on effective management of PLWHA given to health practitioners be extended to relatives caring for infected persons.

This will improve the quality of support PLWHA will receive from home and reduce stigmatization from care-givers which seem to be presently very common.

Finally, considering the level of unemployment observed among PLWHA from this study, it is highly recommended that private and governmental institutions and philanthropic organizations should direct their attention to PLWHA by providing some sort of empowerment (income generating activities) to enable them meet up with their financial needs, that will also go a long way in making them busy thereby reducing redundancy and coping with stigma.

\section{References}

[1].Adedimeji, A. A., Alawode, O. O., and Odutolu, O. (2010). Care support and quality of life outcomes among persons living with HIV in the HAART era. Journal of Harvard school of public Health, 10(5).

[2].Adedimeji, A. A, Alawode, O. O, Odutolu, O. (2010). Impact of care and social support on wellbeing among people living with HIV/AIDS in Nigeria. Iranian Journal of Public Health, 39(2), 30-38.

[3].Agweda, T.O., and Dibua V.A. (2010). The Impact of stigmatization on the acceptance and care for people living with HIV/AIDS in the Society: A case study of civil servants in Auchi. Journal of Social Science, 23(2), 129-134.

[4].Amico, K. R., Toro-Alfonso, J., \& Fisher, J. D. (2005). Evaluation of the information, motivation, behavioral skills model of ART adherence: A replication and extension study. AIDS Care, 17, 661-673.

[5].Ansari, R.M., Ansari, S.Y., Al-Safarini, S., and Ayub, M. (2013). Socio-Ecological approach to selfmanagement of HIV/AIDS: A case study of women patients with HIV virus. Occupational Medicine \& Health Affairs, 1(136).

[6].Asante, O. K (2011). Social support and the psychological wellbeing of people living with 1-IIV/AIDS in Ghana. African Journal of Psychiatry, 15. 340-345

[7].Aranda-Naranjo B. Quality of life in HIV-positive patient. J Assoc Nurses AIDS Care. 2004; 15:20-7.

[8].Aro AR, Jallinoja PT, Henrikson MM, Lönnqvist JK. Fear of acquired immunodeficiency syndrome and fear of other illness in suicide. Acta Psychiatr Scand. 1994; 90:65-9.

[9].Bandura, A. (1994). Self-efficacy and human behavior New York: Academic Press. 1, 71-81.

[10]. Charkhian, A., Fekrazad, H., Sajadi, H., Rahgozar, M., Abdolbaghi, M.H., and Maddahi, S. (2014). Relationship between Health-Related Quality of Life and Social Support in HIV-Infected People in Tehran, Iran. Iranian Journal of Public Health, 43(1), 100-106.

[11]. Cornmana, D.H., Schmiegeb, S.J., Bryanb, A., Benzigerc, T.J., and Fisher, J.D. (2007). An informationmotivation-behavioral skills (1MB) model-based HIV prevention for truck drivers in India. Social Science \& Medicine. 64, 1572-1584.

[12]. Dweck, C.S., and Leggett, E.L. (1998). A Social-Cognitive Approach to Motivation and Personality. Psychological Review, 95(2), 256-273.

[13]. Edmonds, J. K, Paul, M \& Sibley, L. M (2005). Type, content, and source of social support perceived by women during pregnancy: Evidence from Matlab, Bangladesh. Journal of Health, Population and Nutrition, 29(2), 163-173.

[14]. Folasire, O.F., Irabor, A.E., Folasire, A.M. (2012). Quality of life of People living with HIV and AIDS attending the antiretroviral clinic, University College Hospital, Nigeria. African Journal of Primary Health Care and Family Medicine, 4(1).

[15]. Forouzan, A.S., Shushtari, Z.J., Sajjadi, H., Salimi, Y., and Dejman, M. (2012). Social support network among people living with HIV/AIDS in Iran. AiDS Research and Treatment, 20(13). 
[16]. Fisher, W.A., Fisher, J.D., and Harman, J.J. (2003). The information-motivation- behavioral skills model as a general model of health behavior change: Theoretical approaches to individual-level change. In J. Suls \& K. Waliston (Eds.), Social psychological foundations of health (pp. 127-153). London: Blackwell.

[17]. Garcial, R., Ponde, M, Lima M., Souza, A. R., Stoize, S. M \& Badaro, R (2005). Lack of effect of motivation on the adherence of HIV-Positive/AIDS patients to antiretroviral treatment. Brazilian Journal of Infectious Diseases, 9(6), 494-499.

[18]. Heyer, A. S., Mabuza, L. H., Couper, I. D, \& Ogunbanjo, G. A. (2010). Understanding participation in a hospital-based HIV support group in Limpopo Province, South Africa. South African Family Practice Journal, $10(8)$.

[19]. International HIV/AIDS Alliance (2003). The involvement of people living with HIV/AIDS in community-based prevention, care and support services in developing countries. A multi-country diagnostic study. International HI V/A IDS Alliance, 10(5).

[20]. Low-Beer, S., Yip, B., O’Shaughnessy, M., Hogg, R., \& Montaner, J. (2000). Adherence to triple therapy and viral load response. Journal of Acquired Immune Deficiency Syndrome, 23, 360-361.

[21]. Liu, L., Pang, R., Sun, W., Wu, M., Qu, P., Lu, C., and Wang, L. (2013). Functional social support, psychological capital, and depressive and anxiety symptoms among people living with HI V/AIDS employed full-time. BMC Psychiatry, 13(324).

[22]. Madiba, S., and Canti-Sigaqa, V. (2012). Barriers to participate in support groups for people living with HIV: A qualitative study with men receiving antiretroviral treatment in a HIV clinic in Mthatha, South Africa. Global Journal of Health Science, 4(6).

[23]. Mannheimer, S.B., Matts, I.J., Teizak, F., Chesney, M., Child, C., Wu, A.W., and Friedland, G. (2005). Quality of life in HIV-infected individuals receiving antiretroviral therapy is related to adherence. AIDS Care, 17(1), 10-22.

[24]. Martin, F., Caramlau, I. O., Sutcliffe, P., Martin, S., Bayley, J., Choudhry, K. (2010). Self- management interventions for people living with HIV/AIDS (Protocol). The Cochrane collaboration, 10.

[25]. Mannheimer SB, Matts J, Telzak E, Chesney M, Child C, Wu AW, et al. Quality of life in HIV-infected individuals receiving antiretroviral therapy is related to adherence. AIDS Care. 2005; 17:10-22.

[26]. McDowell, T.L., and Serovich, J.M. (2007). The effect of perceived and actual social support on the mental health of HIV-positive persons. AIDS Care, 19(10), 1223-1229.

[27]. Mongkuo, M.Y., Lukas, N., and Taylor, A. (2012). The Effects of Motivation and Knowledge on HIV Prevention Behavior among Historically Black College Students: An Application of the InformationMotivation-Behavioral Skills Model. Greener Journal of Medical Sciences, 2(2), 03 8-044.

[28]. Mweemba, P., Makukula, M.K., and Makoleka, M.M. (2010). Quality of Life and Adherence to Antiretroviral Drugs. Medical Journal of Zambia, 3 7(1).

[29]. National Aids Trust (2010). Psychological support for people living with HIV. National AIDS Trust, http: 1/ nat.org.uklmedialFiles/Publications/July-2010- Psychological-support-for-PLHIV.pdf, 4-23.

[30]. Persson, L., Gullberg, B., Hanson, B. S., Moestrup, T., and Ostergren, P.O. (1994). HIV infection: social network, social support, and CD4 lymphocyte values in infected homosexual men in Malmo, Sweden. Journal of Epidemiology and Community Health, 10(48), 580-585.

[31]. Reis, R.K., Haas, V.J., Santos, C.B., Teles, S.A., Galvao, M.T.G., and Gir, E. (2011). Symptoms of depression and quality of life of people living with HIV/AIDS. Revista Latino Americana de Enfermagem, 19(4), 874-81. Roger, K., Migliardi, P., and Mignone, J. (2012). HIV, social support, and care among vulnerable women. Journal of community psychology, 40(5), 487-500.

[32]. Ryan, R.M., and Deci, E.L. (2000). Intrinsic and Extrinsic Motivations: Classic Definitions and New Directions. Contemporary Educational Psychology, 25, 54- 67.

[33]. Saran, A., Pujari, S., Sengar, A. K., Garg, R., Gupta, I., and Van Dam, J. (2008). Adherence to antiretroviral therapy \& its determinants amongst HIV patients in India. Indian Journal of Medical Research, 127, 28-36.

[34]. Scott, R. Smith, J. C. R, Marcus, C., Brock, T. P., and Chesney, M. (2003). A medication selfmanagement program to improve adherence to HIV therapy regimens. Patient Education and Counseling, 50, $187-199$.

[35]. Sodergard, B., Halvarsson, M., Lindback, S., Sonnerborg, A., Tully, M. P., and Lindbald, A.K. (2012). Differences in adherence and motivation to HIV therapy-two independent assessments in 1998 and 2002. Pharmacy World and Science, 28, 248-256. 
DOI: $10.21522 /$ TIJPH.2013.05.04.Art001

ISSN: $2520-3134$

[36]. Supriya, V. (2013). Coping Mechanism among People Living with HIV in Open Karnataka. Journal of Social Science Research, 1(5), 104-114.

[37]. Swendeman, D., Ingram, B. L, Borus, M. R (2009). Common elements in self-management of HIV and other chronic illnesses: an integrative framework. AIDS Care, 21(10), 1321- 1334.

[38]. Thanh, D. C., Moland, K.M., and Fylkesnes, K. (2012). Persisting stigma reduces the utilization of HIVrelated care and support services in Viet Nam. BMC Health Services Research. 12(428).

[39]. U.S Agency for International Development (2010). Global report on the AIDS epidemic.

[40]. U.S. President's Emergency Plan for AIDS Relief (2012). A Firm Foundation: The PEPFAR consultation on the role of faith-based organizations in sustaining community aid country leadership in the response to HIV/AIDS. Washington: U.S.A.

[41]. Van Tam, V., Larsson, M. Pharris A. Diedrichs. B. Nguyen. H. P. Nguyen C. T. Ho. P D. Marrone G., and Thorson A. (2012). Peer support and improved quality of life of persons living with HIV on antiretroviral treatment: A randomized controlled trial from North-Eastern Vietnam. Health and quality of life outcomes, $10(53)$.

[42]. Webel, A.R., and Higgins P.A. (2012). The Relationship between Social Roles and Self- Management Behaviour in Women Living with HI V/AIDS. Women's health issws. 22(1), 27-33.

[43]. Whetten, K., Reif, S., Lowe, K. and Eldred, L. (2004). Gender Differences in Knowledge and Perceptions of HIV Resources among Individuals Living with HIV in the Southeast. Southern Medical Journal, 97, 342349.

[44]. World Health Organization (2013). The Influence of Social Support on the Lives of HIV Infected Individuals in Low and Middle-Income Countries (LMIC). WHO/HI V/20 13.51. 